\title{
Species richness, biomass and diversity of macroalgal assemblages in tidepools of different sizes
}

\author{
Shuhong Zhuang* \\ School of Biological Science and Chemical Engineering, Yantai University, 264005 China
}

\begin{abstract}
A survey was conducted at 6 bimonthly intervals on tidepools along the rocky shores of Zhifu Tombolo on the north-west coast of the Yellow Sea to determine if the size of tidepools (large, medium and small) determines their macroalgal richness, biomass, and species diversity. Larger tidal pools supported higher macroalgal richness, biomass, and species diversity $\left(H^{\prime}\right)$, and had well distributed macroalgal composition. The seasonal variation in Rhodophyta, Phaeophyta and Chlorophyta composition was similar in large and medium pools, but irregular in small pools, especially with respect to Chlorophyta and Phaeophyta. Patterns of variation in biomass of most macroalgal and total macroalgae taxa were similar in all 3 pool sizes with a peak in August. There was a common pattern of seasonal variation in the number of macroalgal species in all 3 pool sizes, with a peak in the number from April to June, but the number of Rhodophyta, Phaeophyta and Chlorophyta among pool sizes were different. Rhodophyta was the most common group across all pool sizes, and formed the largest biomass, followed by Phaeophyta, and lastly Chlorophyta. This study demonstrated that both pool size and season exert significant impacts on macroalgal species richness, biomass, and species diversity of tidepools.
\end{abstract}

KEY WORDS: Rocky intertidal · Tidepool · Macroalgae · China · Yellow Sea · Zhifu Tombolo Resale or republication not permitted without written consent of the publisher

\section{INTRODUCTION}

Tidepools in the rocky intertidal offer both marine biologists and ecologists ideal experimental areas to study population dynamics, assemblage structure, and success of intertidal communities; this is due to their diverse heterogeneity in spatial arrangement and size, and to the integrity of their community features (Levinton 1982, Duxburg \& Duxburg 1991, Hunt \& Scheibling 1996, Underwood \& Skilleter 1996, Viejo 1997, Delany et al. 1998). Many studies have reported on the ecological structure and function of intertidal assemblages over time (BenedettiCecchi \& Cinelli 1997, Guichard \& Bourget 1998, Neto 2000, 2001, Dhargalka et al. 2001, Paula et al. 2001, Quartino et al. 2001, Falace \& Bressan 2002, Zhuang et al. 2002, 2003, 2004, Schreider et al. 2003), and some studies have been conducted on the assemblages and ecological process of macroalgae in tidepools. van Tamelen (1996), Viejo (1996), Under- wood \& Jernakoff (1984), Underwood \& Skilleter (1996), and Methratta (2004) have used tidepools to study mechanisms of macroalgal zonation, colonization, and assemblage structure. However, few studies have reported on seasonal characteristics of macroalgal assemblages in tidepools of different scales (Zhuang et al. 2002, 2003, 2004).

Scale-oriented ecological studies have demonstrated the importance of size in supporting intertidal populations, communities, and ecosystems (Levin 1992, Bourget et al. 1994, Archambault \& Bourget 1996, Ardisson \& Bourget 1997, Cusson \& Bourget 1997, Guichard \& Bourget 1998). Species richness of a variety of terrestrial taxa increases with area and decreases with isolation (Preston 1962, MacArthur \& Wilson 1967, Hanski 1994, Molles 2002). In the present study, we test whether the size of rocky pools at Zhifu Tombolo (northwest coast of the Yellow Sea, China) is related to the macroalgal species richness, biomass, and species diversity. 


\section{MATERIALS AND METHODS}

Survey area. The present study was undertaken during periods of low tide at bimonthly intervals, for the 12 mo period from October 2001 to August 2002, on the rocky shore of Zhifu Tombolo - the largest and most typical land-tied island in China (Fig. 1). This island has a wide range of substrate heterogeneity that results in a spatial diversity of different sizes of tidepools with welldeveloped macroalgal assemblages. Tidepools used in this study had a similar depth of 20 to $30 \mathrm{~cm}$, and elevation in the mid intertidal zone. van Tamelana (1996) reported that grazing by invertebrate herbivores had an important effect on the abundance of macroalgae in tidepools on the Oregon coast. The density of the chief macroalgal herbivores Littorina brevicula Philippi and Monodonta labio Linnaeus in the tidepools of Zhifu Tombolo is very low ( 3.85 ind. $\mathrm{m}^{-2}$ ), and their distribution is extremely uneven among pools (Zhuang \& Zhang 2001, Zhuang et al. 2003). In order to observe a seasonal pattern of macroalgal assemblage without herbivorous influence, both of these herbivorous gastropod species were removed every $2 \mathrm{~d}$ from the pools during their active season from May to October.

Sampling methods. Selected tidepools were grouped into 3 categories: large pools of surface area 1 to $1.2 \mathrm{~m}^{2}$, medium pools of surface area 0.5 to $0.6 \mathrm{~m}^{2}$, and small pools of surface area less than $0.2 \mathrm{~m}^{2}$. A total of 12 large, 24 medium, and 50 small pools were selected and marked with colored paint on the shore to enable year-round sampling. A $1 \mathrm{~m}^{2}$ wire grid with $20 \times 20 \mathrm{~cm}$ mesh was used for quadrat sampling in all 3 pool sizes.

Pools were not re-sampled, except for large pools where, if necessary, sampling was repeated only after a 6 mo interval so that re-sampling effects could be minimized. The sampling of each pool size was organized according to their intertidal, physical, and biological status for the 6 bimonthly sampling events. In each sampling period 6 small, 4 medium and 3 large pools were used as replicates for each size of pool, and data collected for each pool size was based on quadrat sampling using the wire grid described above. Six quadrats from each large pool, 4 quadrats from each medium pool, and 2 quadrats from each small pool were collected; after the wire grid was placed in the pool and allowed to settle (influenced by the pool's size and geometry), half the quadrats for each pool size were selected from the outer edge of the pool, and the remaining half were selected from within the middle of the pool.

Living macroalgae were carefully separated from the substrate in each quadrat with a knife and placed in a labeled plastic bag. Samples were transferred to the laboratory for identification within $6 \mathrm{~h}$. Identified algae were dried to a constant weight at $80^{\circ} \mathrm{C}$ for biomass calculations (Zhuang \& Zhang 2001, Zhuang et al. 2002).

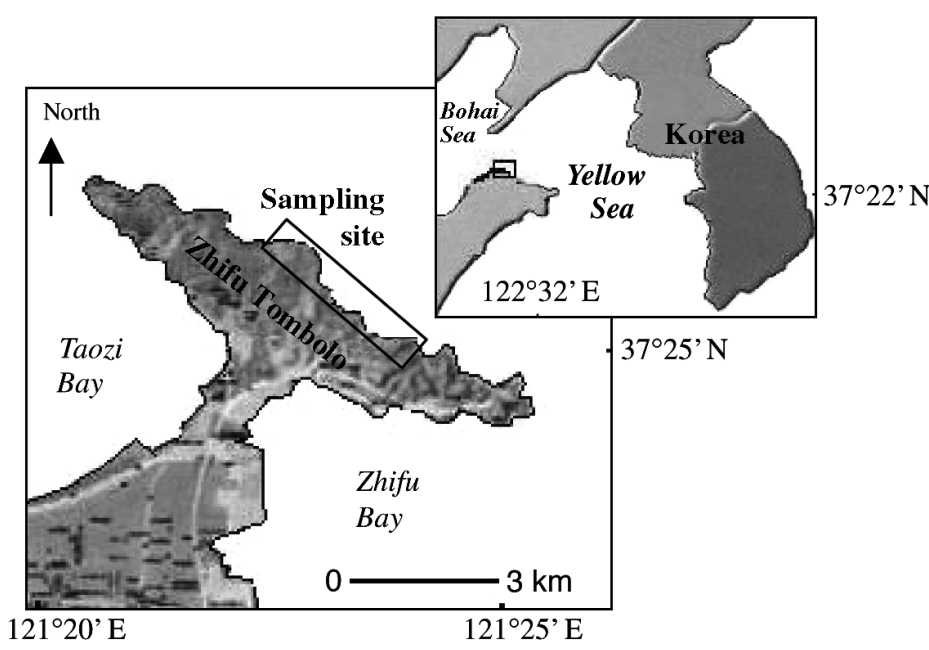

Fig. 1. Locations of Zhifu Tombolo in China and sampling sites

Analytical methods. Relative biomass (RB) was measured with the formula $\mathrm{RB} i=\mathrm{B} i / \Sigma \mathrm{B} i$, where $\mathrm{RB} i$ is the relative biomass of macroalgal species $i$ and $B i$ is the biomass of species $i$. Species diversity was measured using the Shannon-Wiener index $H^{\prime}=-\sum \mathrm{P} i \times \ln (\mathrm{P} i)$, where $H^{\prime}$ is the species diversity index and $\mathrm{P} i$ is the probability of macroalgal species $i$ occurring in each assemblage (in this study, Pi = RBi) (Wilhelm 1968, Magurran 1988, Masson \& Greig 1988).

The effect of pool size and season on species number, macroalgal biomass and Shannon-Wiener index was investigated using ANOVA. In order to assign sampling seasons, mean water temperatures of the corresponding sampling month, named 'sampling temperature', were used: $2.2^{\circ} \mathrm{C}$ in February, $6.2^{\circ} \mathrm{C}$ in April, $17.8^{\circ} \mathrm{C}$ in June, $23.2^{\circ} \mathrm{C}$ in August, $20.5^{\circ} \mathrm{C}$ in October, and $7.1^{\circ} \mathrm{C}$ in December (data obtained from Yantai Oceanography \& Fishery Bureau, 2002).

\section{RESULTS}

\section{Seasonal variation in macroalgal richness and composition}

Both large and medium pools had more macroalgal species than small pools, and they had a similar number of species during the warm season from April to October. However, in February and December, the large pools had 5 to 6 more species than medium pools (Table 1, Fig. 2). Species numbers in all 3 sizes of pools shared a common trend: species number began increasing in February and reached a maximum between April and June, then declined throughout the remainder of the year to December when it reached its minimum. The seasonality of abundance of different 
macroalgal groups varied among the 3 pool sizes. Species number varied significantly with season among the different pool sizes $(p<0.01$, Table 2$)$. There was a common variation in abundance of Rhodophyta in all pools and of Phaeophyta in both the large and medium pools, but there were irregular patterns of abundance of Chlorophyta in all sizes of pools and Phaeophyta in the small pools (Fig. 2).

The main group in all pools throughout the year was Rhodophyta, which comprised more than $50 \%$ of the total species of macroalgae in pools. Phaeophyta accounted for 25 to $32 \%$ of species in large and medium pools, but less in small pools (Table 1, Fig. 2). Chlorophyta had the fewest number of species in all pools throughout the year.

\section{Seasonal variation in macroalgal biomass}

For all pools there was a similar pattern in seasonal change in biomass of total macroalgae, with Rhodophyta obtaining highest biomass in August and lowest biomass in December or February. However, some pool size differences were observed in the seasonal

Table 1. Seasonal variation in macroalgal assemblages (mean species no. and biomass) in large, medium, and small tidepools $(\mathrm{n}=3$ pools $\times 6$ quadrats $=18$ for large pools, $\mathrm{n}=4$ pools $\times 4$ quadrats $=16$ for medium pools, $\mathrm{n}=6$ pools $\times 2$ quadrats $=12$ for small pools)

\begin{tabular}{|c|c|c|c|c|c|c|c|c|c|c|c|c|c|c|c|c|c|c|}
\hline \multirow[t]{2}{*}{ Species } & \multicolumn{6}{|c|}{ Large } & \multicolumn{6}{|c|}{ Medium } & \multicolumn{6}{|c|}{ Small } \\
\hline & Feb & Apr & Jun & Aug & Oct & Dec & Feb & Apr & Jun & Aug & Oct & Dec & Feb & Apr & Jun & Aug & Oct & Dec \\
\hline \multicolumn{19}{|l|}{ Chlorophyta } \\
\hline Enteromorpha intestinalis (L.) Link & 2.25 & 1.12 & & & 0.85 & 3.20 & 2.00 & 1.68 & & & 0.32 & 1.21 & 0.02 & 0.01 & & & & 0.01 \\
\hline Enteromorpha prolifera (Muell.) J. Ag. & & & & & & & & & 0.15 & 0.42 & 0.40 & & & 0.22 & 0.35 & 1.40 & 0.05 & \\
\hline Ulva spp. L. & 0.49 & 3.41 & 11.6 & 20.5 & 25.3 & 15.4 & 0.44 & 5.23 & 8.95 & 11.3 & 11.0 & & & 2.50 & 5.40 & 6.20 & 1.50 & \\
\hline Codium fragile (Sur.) Hariot & & & 5.70 & 8.0 & 6.20 & 0.90 & & & 1.30 & 2.54 & 1.10 & & & & & & & \\
\hline Bryopsis plumose (Huds.) C. Ag. & & 0.12 & 2.35 & 3.02 & 2.04 & 0.05 & & 0.15 & 0.57 & 1.32 & 1.21 & & & & & & & \\
\hline No. of species & 2 & 3 & 3 & 3 & 4 & 4 & 2 & 3 & 4 & 4 & 5 & 1 & 1 & 3 & 2 & 2 & 2 & 1 \\
\hline \multicolumn{19}{|l|}{ Phaeophyta } \\
\hline Sargassum thunbergii (Mert.) O. Kuntze & 5.44 & 16.4 & 435.5 & 32.5 & 22.9 & 13.4 & 0.43 & 0.58 & 2.45 & 3.54 & 2.78 & 1.12 & & & & & & \\
\hline S. fusiforme (Harv.) Setch. & 1.05 & 4.68 & 36.20 & 6.31 & 3.63 & 1.65 & & 0.95 & 2.34 & 4.32 & 2.25 & 0.95 & & & & & & \\
\hline S. kjellmanianum Yendo & & 0.51 & 18.65 & 11.2 & 9.25 & 3.61 & & 0.22 & 0.97 & 2.35 & 0.85 & & & & & & & \\
\hline S.pallidum (Turn.) C. Ag. & 0.87 & 2.34 & 47.65 & 11.0 & 6.89 & 3.24 & & 0.33 & 0.57 & 1.67 & 0.89 & & & & & & & \\
\hline Colpomenia sinuosa (Roth) Derb. et Sol. & 4.15 & 4.35 & 50.75 & & & 1.32 & 5.10 & 5.34 & 1.34 & & & 1.67 & 4.05 & 3.95 & 0.95 & & & 1.11 \\
\hline Undaria pinnatifida (Harv.) Suringer & 3.30 & 3.85 & 6.20 & 6.31 & 3.36 & 1.65 & 0.58 & 1.23 & 2.42 & 2.55 & 2.10 & 0.45 & & & & & & \\
\hline Petalonia fascia (Muell.) Kuetz. & 0.50 & 1.58 & 32.20 & & & & 0.56 & 1.45 & 1.67 & & & & & & & & & \\
\hline Ectocarpus confervoides (Roth) Le Jolis & 0.44 & 0.99 & 91.55 & 0.52 & & & 0.56 & 0.78 & 1.60 & 0.47 & & & 0.45 & 0.98 & 1.65 & 0.22 & & \\
\hline Scytosiphon spp. & 0.21 & 2.03 & 31.68 & & & & 0.32 & 0.85 & 1.23 & & & & & & & & & \\
\hline No. of species & 8 & 9 & 9 & 6 & 5 & 6 & 6 & 9 & 9 & 6 & 5 & 4 & 2 & 2 & 2 & 1 & 0 & 1 \\
\hline \multicolumn{19}{|l|}{ Rhodophyta } \\
\hline Gelidium amansii Lamx. & 14.0 & 33.2 & 217.2 & 21.7 & 6.79 & 9.79 & 10.6 & 23.2 & 10.2 & 13.8 & 3.10 & 4.78 & 2.35 & 3.45 & 1.23 & & & 1.85 \\
\hline Porphyra spp. & 6.35 & 13.2 & 21.52 & & & 2.55 & 5.45 & 7.87 & 2.01 & & & 2.31 & & & & & & \\
\hline Halymenia sinensis Tseng et Chang & 2.65 & 3.05 & & & & 0.06 & 1.34 & 1.58 & & & & 0.02 & & & & & & \\
\hline Ahnfeltia furcellata Okam. & 1.63 & 1.68 & 6.68 & 12.6 & 4.94 & 0.99 & 2.04 & 2.13 & 3.68 & 6.65 & 2.53 & 1.30 & 1.45 & 1.87 & 3.21 & 3.07 & 1.76 & \\
\hline Polysiphonia japonica Harv. & 1.04 & 2.58 & 2.19 & & & 0.56 & 1.11 & 1.85 & 0.96 & & & 0.87 & 0.54 & 0.69 & & & & 0.54 \\
\hline Laurencia spp. & 0.45 & 0.33 & 3.89 & 30.0 & 21.2 & 4.01 & & 0.52 & 3.77 & 9.35 & 10.6 & 2.46 & & & 0.86 & 1.23 & 0.21 & \\
\hline Lomentaria hakodatensis Yendo & 0.32 & 1.56 & 4.68 & 2.39 & 0.45 & 0.08 & 0.15 & 0.17 & 2.54 & 2.10 & 0.56 & & & 0.76 & 1.03 & 0.84 & 0.34 & \\
\hline Ceramium kondoi Yendo & 0.05 & 0.85 & 51.87 & 0.06 & & & 0.07 & 0.53 & 0.98 & 0.10 & & & & & & & & \\
\hline Ceramium japonicum Okam. & 0.03 & 1.03 & 1.94 & 0.40 & & & 0.10 & 1.33 & 2.05 & 0.82 & & & & & & & & \\
\hline Gymnogongrus flabelliformis Harv. & 0.04 & 0.74 & 41.75 & 3.18 & 2.33 & 1.55 & & 0.21 & 1.11 & 3.50 & 1.05 & 0.84 & & & & & & \\
\hline Symphyocladia latiuscula (Harv.) Yamada & 0.01 & 0.01 & 10.55 & 0.99 & 0.10 & 0.22 & & 0.03 & 0.64 & 1.03 & 0.08 & 0.03 & & & & & & \\
\hline Grateloupia filicina C. Ag. & & 3.67 & 79.96 & 3.92 & 1.07 & & & 2.77 & 6.65 & 4.32 & 2.13 & & & 2.14 & 3.55 & 2.12 & 0.95 & \\
\hline Gracilaria verrucosa (Hunds.) Papenfuss & & 5.65 & 521.1 & 7.59 & 2.53 & & & 2.75 & 6.45 & 3.45 & 1.36 & & & 1.65 & 4.34 & 4.33 & 2.03 & \\
\hline Callithamnion corymbosum (Smith) C. Ag. & & 0.77 & 72.01 & 0.09 & & & & 0.88 & 1.75 & 0.33 & & & & & & & & \\
\hline Champia parvula (C. Ag.) J. Ag. & & 0.26 & 1.58 & 3.69 & 2.13 & & & 0.15 & 1.75 & 3.32 & 1.87 & & & 0.20 & 1.43 & 3.55 & 1.21 & \\
\hline Corallina officinalis L. & & 0.21 & 13.23 & 6.87 & 6.57 & 2.55 & & 0.11 & 1.87 & 5.75 & 6.01 & 3.00 & & & 2.97 & 7.50 & 2.31 & \\
\hline Plocamium telfariae Harv. & & 0.08 & B 1.65 & 0.92 & & & & 0.05 & 0.96 & 1.02 & & & & & & & & \\
\hline Pterocladia tenuis Okam. & & & 1.51 & 3.86 & 7.35 & 0.54 & & & 0.97 & 2.77 & 4.88 & 0.42 & & & & & & \\
\hline No. of species & 11 & 17 & 16 & 14 & 11 & 11 & 8 & 17 & 16 & 14 & 11 & 10 & 3 & 7 & 8 & 7 & 7 & 2 \\
\hline Total biomass $\left(\mathrm{g} \mathrm{m}^{-2}\right)$ & 44.2 & 110 & 173 & 198 & 141 & 67.4 & 30.9 & 64.9 & 73.9 & 88.8 & 57.1 & 21.4 & 8.9 & 18.5 & 27.0 & 30.6 & 10.3 & 3.5 \\
\hline Total no. of species & 21 & 29 & 28 & 23 & 20 & 21 & 16 & 29 & 29 & 24 & 21 & 15 & 6 & 12 & 12 & 10 & 9 & 4 \\
\hline
\end{tabular}




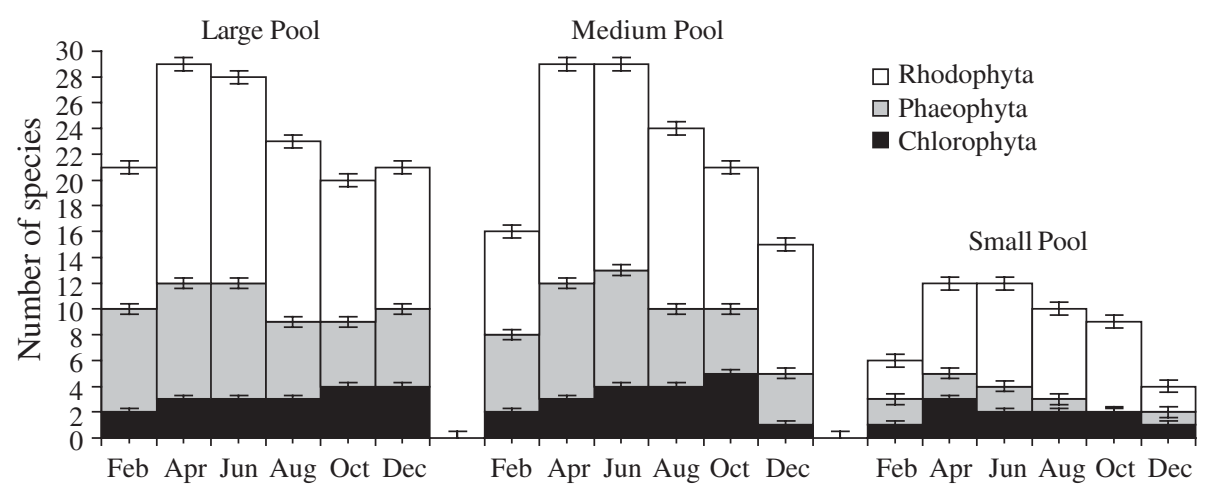

Fig. 2. Seasonal variations in macroalgal richness in 3 sizes of tidepools. Error bars represent $\pm 1 \mathrm{SD}$

change of biomass of Phaeophyta and Chlorophyta (Table 1, Fig. 3). In large and medium pools, biomass levels of Phaeophyta peaked in June and August, but biomass of Chlorophyta peaked in August and October. A continuous decline in biomass of Phaeophyta was observed in small pools from April to December. Generally, Rhodophyta represented the largest macroalgal biomass in all pools, followed by Phaeophyta and then Chlorophyta.

The results also showed that macroalgal biomass was much higher in all pools during the warmer season (June, August, and October) than in the colder season (December, February, and April). Higher macroalgal biomass was observed in larger pools compared to smaller pools during all seasons (Table 1, Fig. 3). Significant differences in macroalgal biomass distribution among different pool sizes $(\mathrm{p}<$ $0.01)$ and among different seasons $(p<0.05)$ were observed (Table 2). Further, the difference in biomass

Table 2. ANOVA of effect of pool size and season (interpreted as sampling temperature) on macroalgal (a) richness, (b) biomass, and (c) species diversity $H^{\prime}$

\begin{tabular}{|lrrrrc|}
\hline Source & df & \multicolumn{1}{c}{ SS } & \multicolumn{1}{c|}{ MS } & \multicolumn{1}{c|}{$F$} & $\mathrm{p}$ \\
\hline (a) & & & & & \\
Pool size & 2 & 808.11 & 404.06 & 94.95 & 0.0000 \\
Temperature & 5 & 272.94 & 54.59 & 12.83 & 0.0004 \\
Error & 10 & 42.56 & 4.26 & & \\
Total & 17 & 1123.61 & & & \\
(b) & & & & & \\
Pool size & 2 & 34277.88 & 17138.94 & 24.33 & 0.0001 \\
Temperature & 5 & 14752.44 & 2950.49 & 4.19 & 0.0259 \\
Error & 10 & 7045.06 & 704.51 & & \\
Total & 17 & 56075.38 & & & \\
(c) & & & & & \\
Pool size & 2 & 1.87 & 0.93 & 16.20 & 0.0007 \\
Temperature & 5 & 1.92 & 0.38 & 6.65 & 0.0056 \\
Error & 10 & 0.58 & 0.06 & & \\
Total & 17 & 4.36 & & & \\
\hline
\end{tabular}

among pool sizes was more pronounced during the warmer season from June to October.

Patterns of macroalgal biomass in both large anmedium pools could be grouped into 2 types: (1) in the cold season, pools were dominated by Gedium amansii, Ceramium spp., Porphyra spp., Halymenia sinensis, Scytosiphon spp., Petalonia fascia, Colpomenia sinuosa, Entermorpha intestinalis; (2) in the warm season, pools were dominated by Ulva spp., Codium fragile, Bryopsis plumose, Sargassum spp., Undaria pinnatifida, Grateloupia filcina, Gracilaria verrucos, Callithamion corymosum, Champia parvula, Corallina officinalis, Plocamium telfariae, Pterocladia tenuis, Ahn-feltia furcellata, Laurencia spp., Lomentaria hakodatensis, Gymnogongrus flabelliformis, and Symphyocladia latiusula. These species died out or disappeared in the colder season (Table 1). However, the seasonal variation in biomass of warm season macroalgae was not observed in small pools, where most species had an irregular or disrupted pattern of occurrence (Table 1).

\section{Seasonal variation in species diversity}

There was a similar variation in $H^{\prime}$ in all pools, which increased from February to June when it reached its peak, before decreasing throughout the rest of the year to December. It was evident that all 3 pool sizes had higher species diversity during the warmer months from June to October than at other times, and both large and medium pools had higher species diversity throughout the year compared to small pools (Fig. 4). Higher species diversity was observed in medium pools compared to large pools during the period from June to October, but the reverse situation was observed from December to April. It was found that both pool size and season had significant effects on species diversity, but that the effect of pool size was more significant (Table 2). 


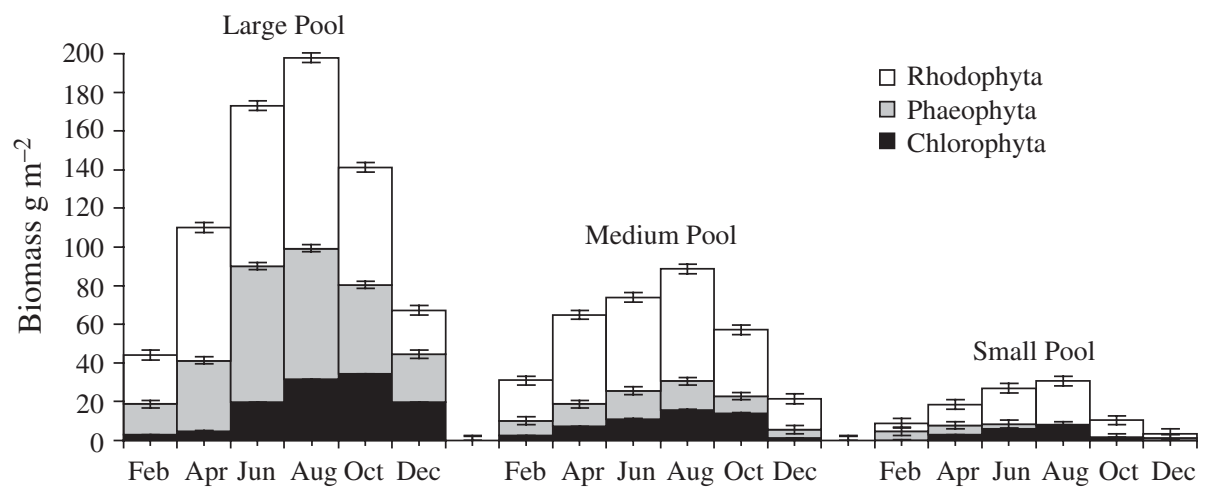

Fig. 3. Seasonal variations in macroalgal biomass in 3 sizes of tidepools. Error bars represent \pm 1 SD

\section{DISCUSSION}

\section{Composition and number of species}

Temperature requirements for growth and development of intertidal macroalgae determine the composition and number of species of flora in intertidal zones (Zeng 1962, 1983, Zeng \& Zhang 1962, Zhuang \& Zhang 2001). During the period between April and June, species numbers were greatest in all tidepools because the seawater temperature at that time was not only suitable for the cold water species but was also sufficiently warm to support vigorous growth of warmtemperate species. Since most macroalgal species on the rocky shores of Zhifu Tombolo are eurytopic warmtemperate species, the number of species found in pools was higher in the warmer season than in the cold season. Tidepools with a larger area were capable of supporting a greater number of macroalgal species than smaller pools, which agrees with the results of Underwood \& Skilleter (1996). The data also support the idea that tidepools of medium size 0.5 to $0.6 \mathrm{~m}^{2}$ are able to maintain similar species assemblages to those in large pools in the moderate and warm seasons between April and October.

The seasonal variation in macroalgal species in all pools generally agreed with results of studies made on

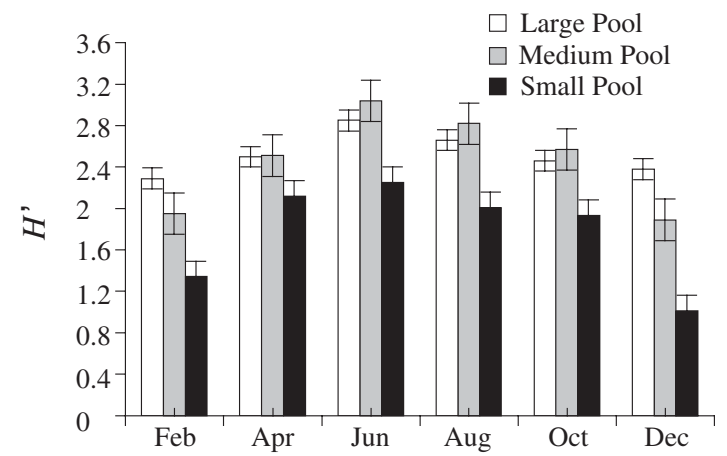

Fig. 4. Seasonal variations in species diversity $\left(H^{\prime}\right)$ in 3 sizes of tidepools. Error bars represent $\pm 1 \mathrm{SD}$ the rocky shores along the north-west coast of the Yellow Sea (Zeng 1962, Zeng \& Zhang 1962, Liu \& Zhang 1994, 1995, Liu et al. 1999). Rhodophyta were the dominant component in species number and biomass in all pools, followed by Phaeophyta, and lastly Chlorophyta. Most species identified were warm temperate species.

The success of dominant species throughout the seasons was clearly demonstrated in tidepools, but was more evident in large and medium pools than in small pools. The fact that the dominant warm-water Sargassum spp. and the subtropical Laurencia spp. were the most important macroalgae in both large and medium pools but were absent from the small pools suggests that there must be a major distinction in microenvironment among large, medium and small pools. The nature of this distinction, however, remains unclear and requires further study.

\section{Macroalgal biomass}

Seasonal variation in total macroalgal biomass, and in particular that of Rhodophyta, showed a common pattern in all tidepools: the highest biomass was obtained in August and the lowest in December or February, which was similar to results of previous studies of intertidal macroalgae biomass in this region (Liu et al. 1999, Zhuang et al. 2003, 2004). The fact that larger pools had higher macroalgal richness and biomass among the major algal divisions suggests that pools with a surface area larger than $1 \mathrm{~m}^{2}$ in this coastal region are able to maintain an abundance of species richness and biomass similar to that of the open environment in the local rocky intertidal, where the number of species, biomass, and species diversity varied by 18 to 33 species, 70 to $210 \mathrm{~g} \mathrm{~m}^{-2}$, and 1.8 to $3.2\left(H^{\prime}\right)$, respectively (Zhuang \& Zhang 2001, Zhuang et al. 2003, 2004). When compared to large pools and the open rocky intertidal, medium pools with a surface area of 0.5 to $0.6 \mathrm{~m}^{2}$ were able to maintain a similar diversity of species but not a similar 
biomass, while small pools with an area less than $0.2 \mathrm{~m}^{2}$ were unable in any season to sustain a distribution of species numbers or biomass comparable to that of large and medium pools.

Zhuang et al. (2003) and Mei \& Hou (1988) reported that there was a distinct difference in both species numbers and biomass between the warm seasons of summer and autumn (June to October), and the cold seasons of winter and spring (December to April) on the rocky shores of Yantai and Weihai in this coastal region. The seasonal change in biomass of each macroalgal species depends in part on temperature for growth (Zeng \& Zhang 1962, Zeng 1983). During cold periods, pools were generally dominated by coldwater species such as Gelidium amansii, Porphyra spp. and Colpomenia sinuos, and in the warm season by warm-water and subtropical species such as Sargassum thunbergii, Ulva spp. and Laurencia spp. This study demonstrated that similar seasonal biomass patterns occurred in all sizes of pools, but that they were more pronounced in larger pools than in smaller pools. Although Zhuang et al. (2003) expected that there would be qualitative and quantitative differences in macroalgal assemblages in different sizes of pools, this is the first study to clearly demonstrate this phenomenon.

\section{Species diversity}

Similar to the macroalgal assemblages on rocky shores of this region studied by Zhuang et al. (2002, $2003,2004)$, the highest species diversity of macroalgae in pools occurred in June and continued until October. The difference between tidepools and the open rocky shore was that high values in species number, biomass, and species diversity were significantly correlated with pool size (Zhuang et al. 2003). This result agrees with a common phenomenon observed among intertidal assemblages of rocky shores, where favorable conditions lead to proliferation of a few dominant species at the expense of others (Viejo 1997). Peak biomass in August was dominated by relatively fewer species in open shore communities, whereas tidepools retained an uneven biomass distribution among different groups of species (Viejo 1997, Zhuang et al. 2002). Although not statistically significant, greater species diversity in medium pools from April to October resulted from a more evenly distributed biomass of different macroalgal taxa during this period. The lower species diversity in large pools during this period was perhaps due to vigorous growth of the shrubby and foliage-forming dominant algae of Phaeophyta and Chlorophyta.

\section{CONCLUSION}

The size of tidepools in the interidal zone of Zhifu Tombolo plays a key role in determining macroalgal assemblages in terms of species number, biomass, and species diversity. Although larger pools supported higher macroalgal species richness, biomass, and species diversity, which agrees with the 'island biogeography' hypothesis of species number and area proposed by MacArthur \& Wilson (1967), in ecological terms the scales of different pool sizes are not comparable to scales of land and islands. Tidepools larger than $1 \mathrm{~m}^{2}$ surface area were able to maintain macroalgal assemblages that were similar in species number, biomass, and species diversity to those of open rocky shores in this area, while pools smaller than $0.2 \mathrm{~m}^{2}$ were not. Medium pools ( 0.5 to $0.6 \mathrm{~m}^{2}$ ) were only capable of maintaining an assemblage similar to the large pools from April to October. Therefore pool size and season had significant influences on the macroalgal richness, biomass, and species diversity in tidepools of Zhifu Tombolo.

Acknowledgements. I am grateful to the local monitoring station of the Yantai Department of Oceanography and Fishery Bureau for their assistance in monitoring the survey area and collecting macroalgae. I also thank my Canadian colleague, Dr. Neil Bourne of Pacific Biological Station, Nanaimo, B.C., for his revision and improvement of this manuscript.

\section{LITERATURE CITED}

Archambault P, Bourget E (1996) Scales of coastal heterogeneity and benthic intertidal species richness, diversity and abundance. Mar Ecol Prog Ser 136:111-121

Ardisson PL, Bourget E (1997) A study of the relationship between freshwater runoff and benthos abundance: a scale-oriented approach. Estuar Coast Shelf Sci 45: 533-545

Benedetii-Cecchi L, Cinelli F (1997) Spatial distribution of algae and invertebrates in the rocky intertidal zone of the Strait of Magellan: Are patterns general? Polar Biol 18:3337-3343

Bourget E, deGuise J, Daigle G (1994) Scale of substratum heterogeneity, structural complexity, and the early establishment of a marine epibenthic community. J Exp Mar Biol Ecol 181:31-35

Cusson M, Bourget E (1997) Influence of topographic heterogeneity and spatial scales on the structure of the neighbouring intertidal endobenthic macrofaunal community. Mar Ecol Prog Ser 150:181-193

Delany J, Myers A, McGrath D (1998) Recruitment, immigration and population structure of two coexisting limpet species in mid-shore tidepools, on the west coast of Ireland. J Exp Mar Biol Ecol 221:221-230

Duxburg AC, Duxburg AB (1991) Ocean. Wm. C. Brown, Dubuque, IA

Falace A, Bressan G (2002) Evaluation of the influence of inclination of substrate panels on seasonal changes in macrophytobenthic assemblage. ICES J Mar Sci 59:116-121 
Guichard F, Bourget E (1998) Topographic heterogeneity, hydrodynamics, and benthic assemblage structure: a scale-dependent cascade. Mar Ecol Prog Ser 171:59-70

Hanski I (1994) Spatial scale, patchiness and populations dynamics on land. Phil Trans R Soc Lond B 343:19-25

Hunt HL, Scheibling RE (1996) Structure and dynamics of mussel patches in tide-pools on a rocky shore in Nova Scotia. Can Oceanogr Lit Rev 43:491-501

Levin SA (1992) The problem of pattern and scale in ecology. Ecology 73:1943-1967

Levinton JS (1982) Marine ecology. Prentice-Hall, Englewood Cliffs, NJ

Liu DY, Wang ZY, Song T (1999) Study of the benthic algae in the Littoral of Qingdao coast. Chin J Oceanol Limnol 3:36-40

Liu JH, Zhang YH (1995) Preliminary study on the benthic algae in the intertidal region of Muguan Island. Chin J Oceanol Limnol 1:80-86

MacArthur RH, Wilson EO (1967) Theory of island biogeography. Ecology 42:594-598

Magurran AE, (1988) Ecological diversity and its measurement. Princeton University Press, Princeton, NJ

Masson P, Greig SP (1988) Quantitative plant ecology. Blackwell Science Publications, London

Mei JX, Hou XG (1998) The seasonal change of marine algae in Weihai, Shandong Province. Chin J Oceanol Limnol 3:51-56

Methratta ET (2004) Top-down and bottom-up factors in tidepool communities. J Exp Mar Biol Ecol 299:77-96

Molles MC (2002) Ecology. McGraw-Hill, Singapore

Neto AI (2000) Ecology and dynamics of two intertidal algal assemblages on the littoral of the Island of São Miguel (Azores). Hydrobiologia 432:135-147

Neto AI (2001) Macroalgal species diversity and biomass of subtidal assemblages of São Migual (Azores). Helgoland Mar Res 55:101-111

Paula J, Fidalgo P, Martin A, Gove D (2001) Patterns of abundance of seagrasses and associated infaunal assemblages at Inhaca Island, Mozambique. Estuar Coast Shelf Sci 53:307-318

Preston FW (1962) The canonical distribution of commonness and rarity. Part II. Ecology 43:410-432

Quartino M, Kloeser H, Schloss I, Wienke C (2001) Biomass and associations of benthic marine macroalgae from the

Editorial responsibility: Kenneth L. Heck Jr (Contributing Editor), Dauphin Island, Alabama, USA
Potter Cove (King George Island, Antarctica) related to depth and substrate. Polar Biol 24:349-355

Schreider MJ, Glasby TM, Underwood AJ (2003) Effects of height on the shore and complexity of habitat on abundances of amphipods on rocky shores in New South Wales, Australia. J Exp Mar Biol Ecol 293:57-71

Underwood AJ, Jernakoff P (1984) The effect of tidal height, wave-exposure, seasonality and rock-pools on grazing and the distribution of intertidal macroalgae in New South Wales. J Exp Mar Biol Ecol 75:71-96

Underwood AJ, Skilleter GA (1996) Effects of patch-size on the structure of assemblages in rock pools. Oceanogr Lit Rev 43:1135-1144

van Tamelen PG (1996) Algal zonation in tidepools: experimental evaluation of the roles of physical disturbance, herbivore and competition. J Exp Mar Biol Eol 201:197-231

Viejo RM (1997) The effect of colonization by Sargassum muticum on tidepool macroalgal assemblages. Oceanogr Lit Rev 44:1527-1536

Wilhelm JL (1968) Use of biomass units in Shannon's formula. Ecology 49:153-156

Zeng CQ (1962) Economic algal flora of China. China Science Press, Beijing

Zeng CQ (1983) Common seaweeds of China. China Science Press, Beijing

Zeng CQ, Zhang JP (1962) Analysis on algal flora of western coast of Yellow Sea: the temperature characteristics of algal flora. Chin J Oceanogr Limnol 41:49-59

Zhuang SH, Zhang M (2001) Biodiversity investigation. II. The biodiversity in intertidals of Yantai littoral regions. Shandong Map Publisher, Jinan

Zhuang SH, Chen LX, Wang ZQ (2002) Assemblage diversity patterns in intertidal assemblages of three southern islands of Changshan Archipelago. Chin J Appl Ecol 13: 21-31

Zhuang SH, Chen LX, Sun L (2003) The seasonal variation pattern of benthic algal community structure in rocky intertidal zones of southern Changshan Island. Chin J Adv Mar Sci 21:34-41

Zhuang SH, Chen LX, Sun L (2004) Seasonal variation patterns of the benthic macroalgal community in a waveeroded granite intertidal at Longxudao, the north-west coast of the Yellow Sea. Chin J Mar Sci 28:47-54

Submitted: March 18, 2004; Accepted: September 1, 2005

Proofs received from author(s): January 13, 2006 